\title{
EXPLORATION OF NEW INNOVATION SCENARIOS THROUGH THE REINTERPRETATION OF LOCAL MATERIAL CULTURE IN THE MASTER IN DESIGN
}

\author{
João MARTINS ${ }^{1,2}$, Luis MOTA ${ }^{1,2}$ and Rui CAVALEIRO ${ }^{1}$ \\ ${ }^{1}$ Polytechnic Institute of Viana do Castelo \\ ${ }^{2}$ Research Centre for Architecture, Urbanism and Design (CIAUD), Faculty of Architecture, \\ University of Lisbon
}

\begin{abstract}
Our master's degree in integrated design is a teaching project designed to protect, predominantly, a series of professional specialisations. It is a precursor to the mission of the educational institution where it works, namely in its search for the economic, social impact and cultural in the region where it is inserted. The theme of this year's project challenged the students to develop new perspectives on the local tableware whose style that has contributed to the characterisation of the city's identity. From the concept of contemporaneity, and the idea of the need for a "new filling", in keeping with the new aestheticfunctional and symbolic requirements of its inhabitants, the project aimed to contribute to the recovery of the image of the city as an important centre of dynamisation of an industrial sector with tradition in the region. In establishing partnerships with entities and companies, the project work was supported by the City Museum, City Hall, Industries of the Region and professionals in various areas of design and related (architecture, engineering, anthropology, etc.). The realisation of the project in design implied a phased work process from the research on the problem, through the generation of ideas until its materialisation. In the end, the project showed that the dishes drawn here may in the future achieve great notoriety as a result of the good interpretation of the material culture that preceded them, and the quality of their design. It is concluded that the recovery of the history of the city's ceramics can contribute to stimulate more innovation and creativity in the future.
\end{abstract}

Keywords: Product design, ceramics, cultural heritage, master's in design

\section{INTRODUCTION}

The present article is intended for the presentation and analysis of the work developed in the course of Integrated Project Laboratory, of the master's in Integrated Design. This project consists in the development of new perspectives for the Viana's tableware, whose style that has contributed to the characterisation of the city's identity. Having as a base concept the "contemporaneity", this project arises with the intention of dynamising and recovering the image of this industrial and traditional sector of the region of Viana do Castelo, always attending to the new aesthetic-functional and symbolic requirements of its inhabitants. The article aims to develop new concepts for the historical "Viana's Tableware", whose style has always contributed to this, to characterise the identity of the city of Viana do Castelo. Having as main reference the concepts of contemporaneity, we intend to develop new pieces with an aesthetic and functional character consistent with the symbolism to which these objects refer not only to the inhabitants, but also to the consumers and collectors of this archetype of product. The emergence of the Viana pottery in the eighteenth century obtained a very strong acceptance and appreciation on the part of the Portuguese and, mainly, by the inhabitants of the city, which led to these artefacts becoming undisputed historical symbols of the city of Viana do Castelo. However, the political conjuncture of the time generated a sharp fall in sales, as well as the partial replacement of these articles by others of foreign origin, with lower costs. It is then in this context that the development and production of new articles are planned that will allow the resurgence of the Viana Tableware, undoubtedly having as a central premise the respect and consideration of the individualities inherent in traditional pieces. 


\section{THE DISH OF VIANA}

It was from the sixteenth century that the Vianese navigators, and all activity related to maritime navigation, allowed great successes to the city of Viana do Castelo. At this time, a wealthy social class emerged that implemented magnificent palaces filled with decorative elements in the Manueline style. The magnificence of this architecture combines the magnificence of pieces for the interiors where porcelain and earthenware pieces, many of them of oriental origin, could not be missing.

Over the years, Viana do Castelo has become one of the most important ceramic centres in Portugal, creating notorious pieces of high quality and artistic value.
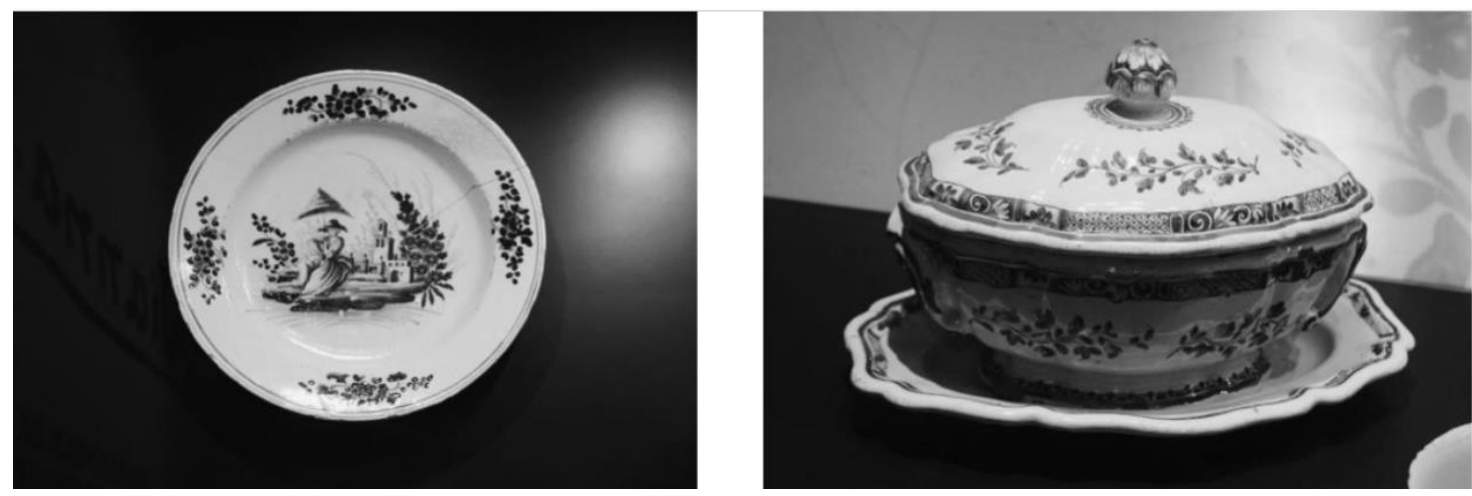

Figure 1. and 2. PLATO Factory of Viana Brand: Vianna Alt. $4,6 \times$ dia. $33.8 \mathrm{~cm}$ Location: Museum of Decorative Arts of V.C. TERRINA WITH COVER AND TRAVEL Fábrica de Viana Brand: VIANNA Terrina - alt. 21 x comp. $29 \mathrm{~cm}$ Travessa - alt. 4 x comp. $24,3 \mathrm{~cm}$ Place: Museum of Decorative Arts of V.C.

In 1950 the use of porcelain was implemented, with influence on Vista Alegre dishes. The factory of Meadela started to produce pieces in porcelain, utility utensils entirely decorated by hand and cooked at high temperatures.

However, it was not possible to obtain a paste equal to the original or the same colours, causing the production of crockery in fine stoneware with paint under glass.

Nowadays, the pieces executed in this factory are called "Regional Crockery of Viana".
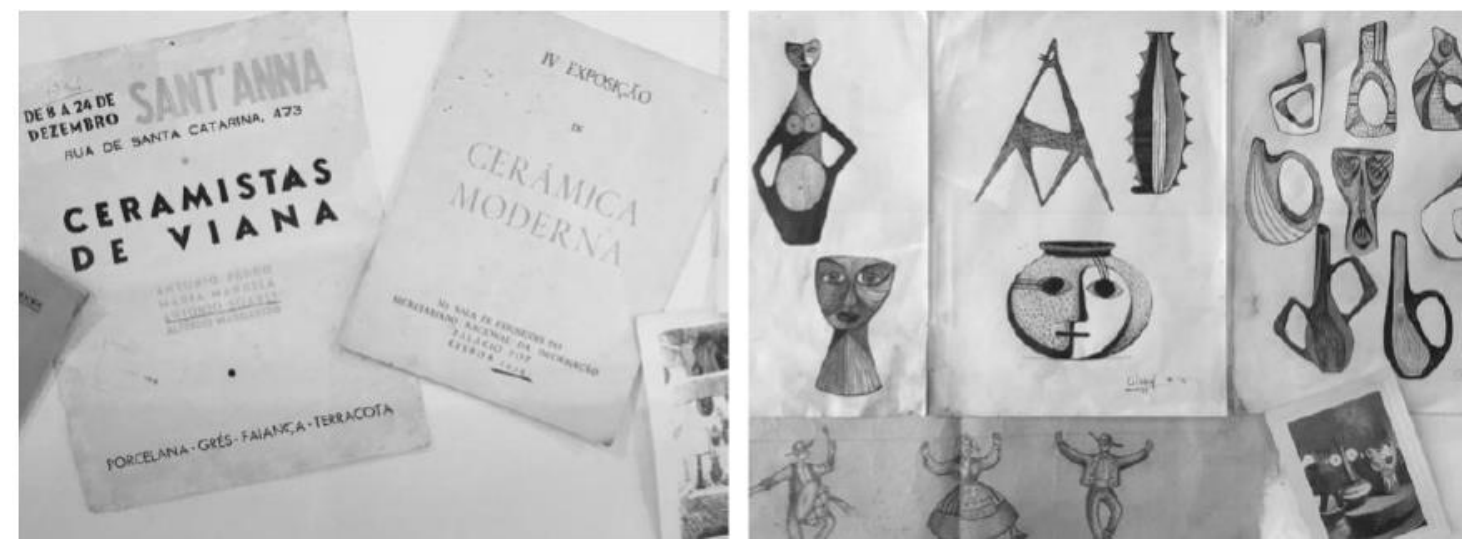

Figure 3 - Vintage Posters (1954) and sketches for new ceramic products (1955)

\section{SOME CHARACTERISTICS OF THE VIANA EARTHENWARE}

1. The word Vianna associated with a reference number

2. Bottles and drumsticks - set of jars and straws with about two hundred pieces in earthenware.

3. Cartridges and sanders - utensils of the category of objects without utilitarian use, they maintained constant presence in places where it was customary to write.

4. Blue as the background colour - Viana's factory produced, mainly, utilitarian crockery covered by a light blue enamel (vintage blue).

5. Feather relief with landscape - decoration inspired by models produced in England in the third quarter of the 18th century and was used in the first productions of the Viana factory. 
6. Building motif with many windows - There is a set of unbranded pieces in which a motif painted in vinous blue - a building with many windows - is associated either with a feathered motif or with an oak leaf motif.

7. Elongated floral composition on the rim of the dishes.

\section{INTEGRATED PROJECT LABORATORIES}

The IPVC master's degree in Integrated Design, a teaching project designed to ensure predominantly the acquisition of a specialisation of a professional nature, is a forerunner of IPVC's mission, namely in its search for the economic, social and cultural impact in the region where it is inserted. This cycle of studies leading to the master's degree lasts three semesters and integrates a specialisation course consisting of an organised set of curricular units taught in the first two semesters, including the curricular unit of Integrated Project Laboratory.

\subsection{Theme / problem of the project}

The theme of this year's project, entitled "New Viana Tableware", challenges students to develop new perspectives on the so-called Viana Tableware, whose style that has contributed to the characterisation of the city's identity. From the concept of contemporaneity, and the idea of the need for a "new filling" for a "new architecture", in keeping with the new aesthetic-functional and symbolic requirements of its inhabitants, the project intends to contribute to the recovery of the image of Viana of the Castle as an important centre of dynamisation of an industrial sector with tradition in the region. In the end, the project aims to show that the dishes here designed may in the future achieve great notoriety as a result of the good interpretation of the material culture that preceded them, and the quality of their design. "(...) it is augured that the recovery of the history of Viana's fate can contribute to stimulate innovation and creativity." [1]

\subsection{Pedagogical model}

The teaching-learning dynamics is centred on the Studio-Based Learning model where the students (apprentices) is directed under the close supervision of the teachers (masters). The project work begins by being cooperative, involving each student in a joint process of analysis and definition of the problem, but where the solution will be developed individually. The fieldwork made the students, take place to a better view about the use of the Viana`s tableware. Besides that, they developed a questionnaire to the public focusing on the "Viana Tableware", aiming at a deeper knowledge about the aesthetic, functional and symbolic attributes related to these products. The questionnaire [2] was an important tool for collecting information. Ninety-six replies were obtained, on which some of the most relevant issues were examined and the following conclusions were drawn.

\subsection{Partnerships}

By launching bridges with various entities and companies, the teaching team intends to provide students with various contacts that enrich their knowledge on the subject. In this sense, the partnerships with Museums, City Hall, Industries of the Region and professionals in several areas of design and related (architecture, engineering, anthropology, etc.) seem obvious to us.
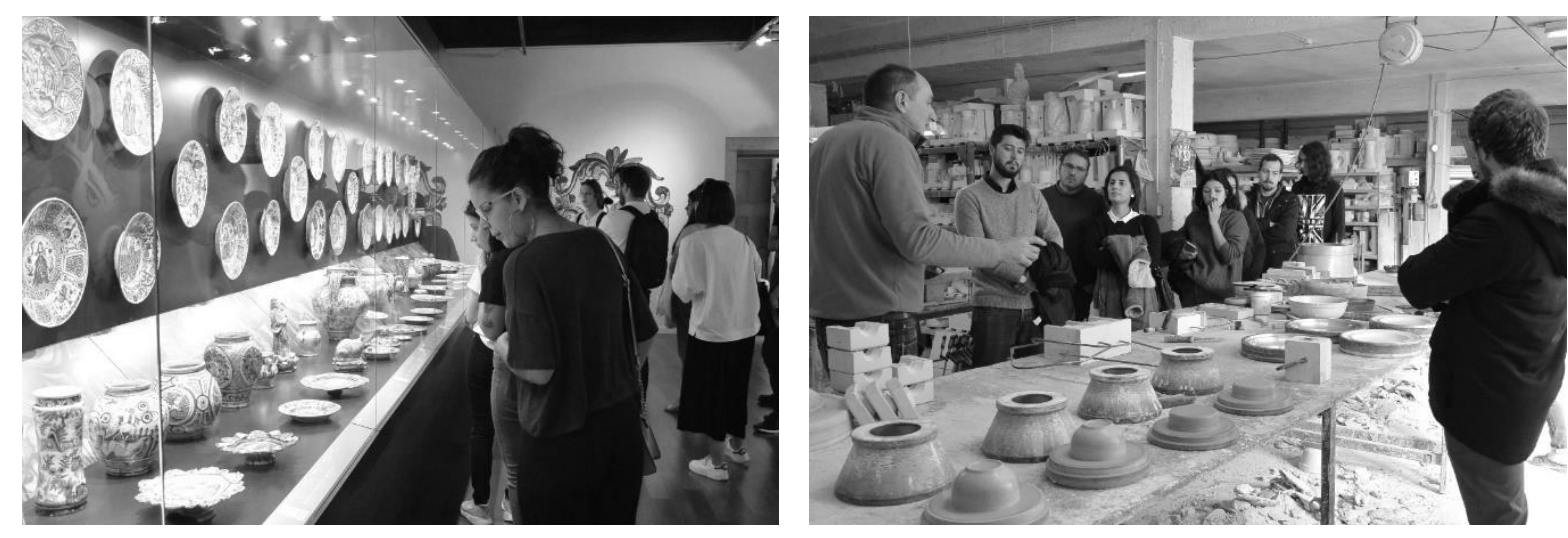

Figure 4. and 5. Visit to the collections of the Viana do Castelo Museum of Decorative Arts, and to the Meadela factory, where students can see the production process 


\section{DESIGN PROCESS}

The realisation of a project in design implies a phased work process from the research on the problem, through the generation of ideas until its materialisation. The good use of supports, tools and techniques associated with the design process in order to obtain results in each of the phases that together guide the project to a solution based on reasoned argumentation.

\subsection{Analysis and definition of the problem}

Defining and questioning the problem at the beginning of the design process becomes fundamental to know all the aspects that cover it. In this first phase, a broad thinking is expected so as not to limit the success of the results. Asking, observing, thinking and learning are verbs that should direct action.

\subsection{Idea generation}

"Sometimes an idea can be our worst enemy, especially if it prevents us from thinking about alternatives." [3] In this creative phase, melancholy or stagnant approaches are discouraged, and those that are more agitating, and transforming are promoted, which foster cultural changes, since this is considered the most appropriate way to construct new meanings for the Viana Tableware and its possible variants. In order to facilitate acceptance by the target public, it is necessary to integrate knowledge about their functional needs and socio-cultural interactions, use of artefacts, emotional aspects, habits, and behaviours associated with context.

\subsection{Conceptual synthesis}

Reducing the various ideas to a dominant concept helped frame the direction to follow for a particular design approach and evolve in the design process. The quality of the concept largely determined the acceptance of a new solution that was expected to be creative and divergent.
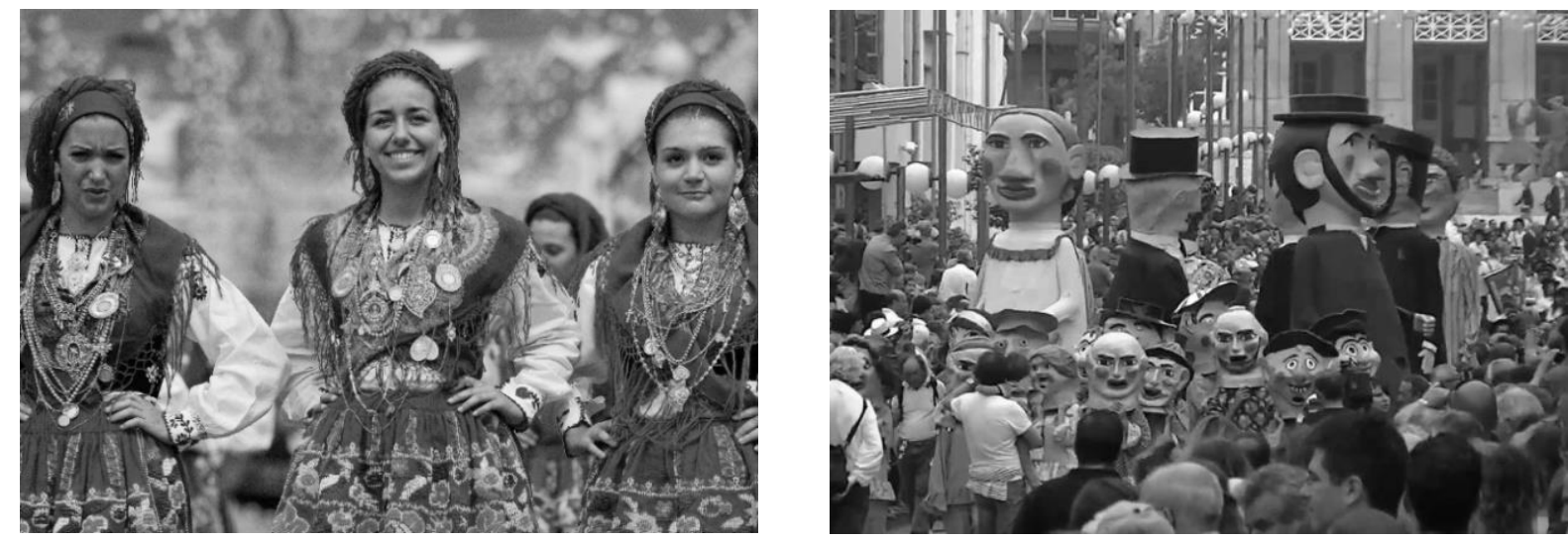

Figure 6. and 7. Some influences for the project: The Historical and Ethnographic Courtship of Romaria in Honour of Our Lady of the Agony
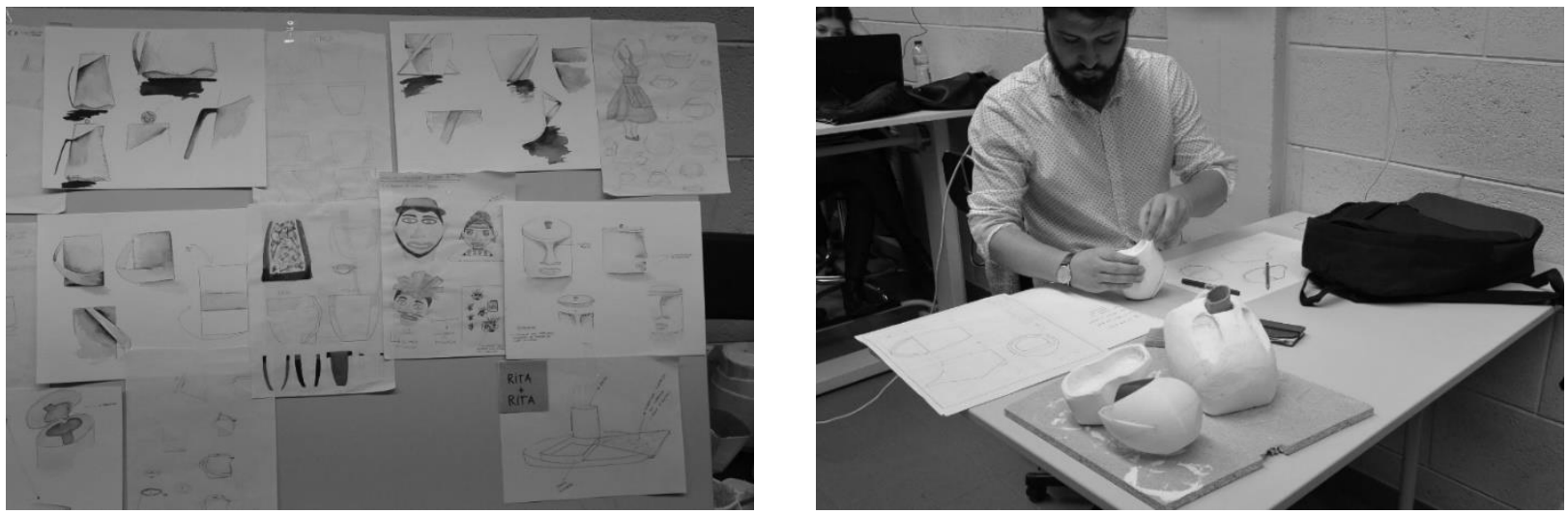

Figure 8. and 9. Ideas for new ceramic products inspired by the cultural traditions of the region. Student modelling the idea selected in the previous phase 


\subsection{Modelling and Prototyping}

Modelling concepts physically was essential to attest to the possibility of being able to become threedimensional realisations. This allowed to prove the functionality, usability, ergonomics, proportions and shapes of these concepts and to continue to develop them. The approach to the concrete solution was made through physical prototypes in real size and perfectly functional. In addition to testing the application of materials, technologies and manufacturing processes, the prototype gave the possibility to submit it to the users who jointly guided the decision making.

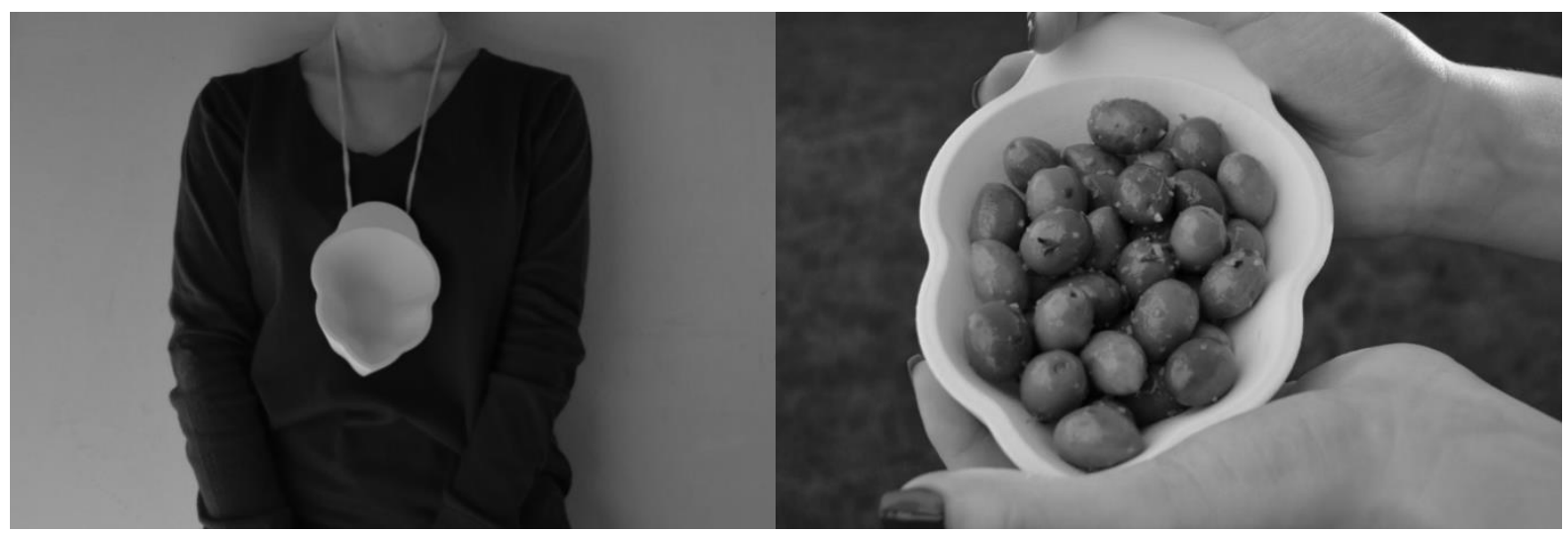

Figure 12. Example of new product of ceramic: bowl to bring to the breast serving small amount of food

\subsection{Communication}

At this time, students were aware that communication tools are especially valuable in validating a solution. At this stage, they could be considered as elements that constituted a visual presentation, the drawings, the virtual model, the prototype, the use of the product and their possible contexts.

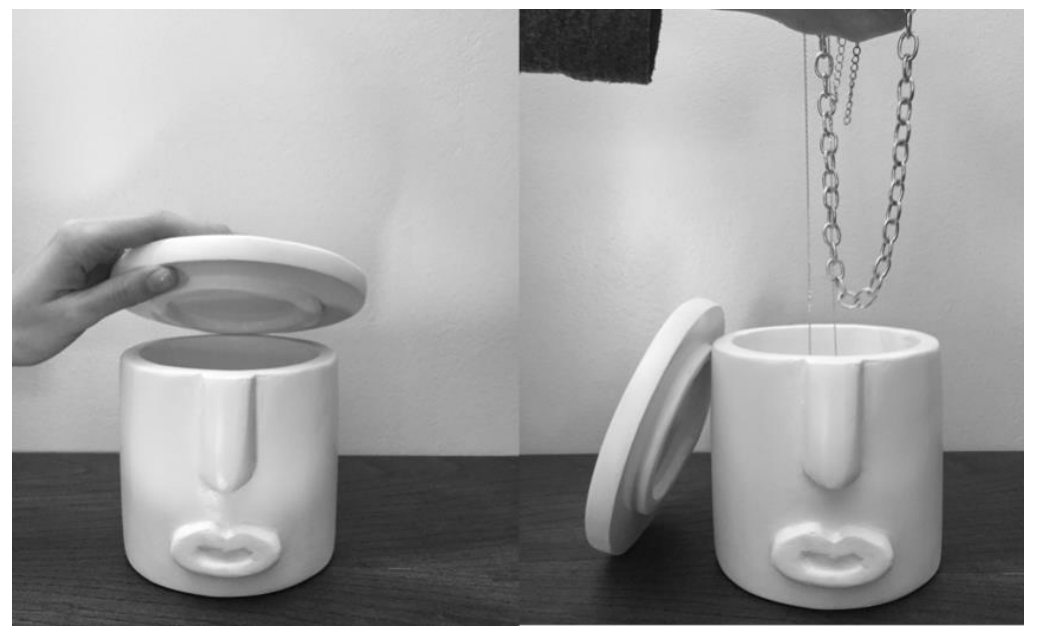

Figure 13. Example of new product of ceramic: pots inspired by the culture of giant figures

\section{CONCLUSIONS}

The approach to the academic project is no longer assumed like an exercise that the students must present solutions to a programme presented in the subjects of the course. Instead, they must be able to assume the project as a motor of development that promotes and manage most of the diverse relationships and partnerships that allows to obtain results and exceed the class room space and have consequences in the most diverse areas of the contemporary societies. The academic exercise of project assumed as a factor of local cultural integration, of specialised industrial production, and the recovery of values, meanings and symbols, which reflect the essence of a culture of a particular country and region. To study, understand and thinking in the specific context is the adequate methodology to understand the user perception, needs, desires and expectations, to adequate the solutions to industrial production, to add 
value to the region, his local entities and to the society in general. To promote the reflection about the true pertinence and essence of the reasons that support the design and execution of new objects, to alert students to their capacity of observation about the reality they encounter and interact in order to take on the design activity as a permanent alert, are goals that determine the project, appealing to the pedagogical character about the value of the objects / products, and consequently on the subject of design. As a result of the project the achieve of new perspectives about the theme allows to rethink and redesign the objects that belong to our history, our culture, now through the filter of contemporaneity, current constraints, current experiences, expectations and contemporary values. At the end is possible to achieve the importance of academic knowledge as promoter and motivator of new challenges capable of raising the reflection on the paradigm of design and the consequence of the intervention of design in the improvement of the populations everyday life, of adding value to industry, commerce and cultural agents and other entities of public organisation and management.

\section{REFERENCES}

[1] Reis A.M. A Louça de Viana. Lisboa: Livros Horizonte, 2003.

[2] Carmo H. and Ferreira M.M. Metodologia da investigação [Em linha] : guia para autoaprendizagem. Lisboa: Universidade Aberta, 2015. 316 p. (eUAb. Universitária; 9). ISBN 9789726747598.

[3] Lupton E. (Org.) - Intuição, Ação, Criação: Graphic design thinking. Barcelona: Editorial Gustavo Gili, 2011. 